\title{
Sites of strong Rec12/Spo11 binding in the fission yeast genome are associated with meiotic recombination and with centromeres
}

\author{
Katja Ludin • Juan Mata $\cdot$ Stephen Watt • \\ Elisabeth Lehmann • Jürg Bähler • Jürg Kohli
}

Received: 21 November 2007 /Revised: 14 March 2008/Accepted: 14 March 2008 / Published online: 1 May 2008

(C) Springer-Verlag 2008

\begin{abstract}
Meiotic recombination arises from Rec12/Spo11dependent formation of DNA double-strand breaks (DSBs) and their subsequent repair. We identified Rec12-binding peaks across the Schizosaccharomyces pombe genome using chromatin immunoprecipitation after reversible formaldehyde cross-linking combined with whole-genome DNA microarrays. Strong Rec12 binding coincided with previously identified DSBs at the recombination hotspots ura $4 \mathrm{~A}$, $m b s 1$, and $m b s 2$ and correlated with DSB formation at a new site. In addition, Rec12 binding corresponded to eight novel conversion hotspots and correlated with crossover density in segments of chromosome I. Notably, Rec12 binding inversely correlated with guanine-cytosine (GC) content, contrary to findings in Saccharomyces cerevisiae. Although both replication origins and Rec12-binding sites preferred AT-rich gene-free regions, they seemed to exclude each other. We also uncovered a connection between binding sites of Rec12 and meiotic cohesin Rec8. Rec12-
\end{abstract}

Communicated by E.A. Nigg

Electronic supplementary material The online version of this article (doi:10.1007/s00412-008-0159-3) contains supplementary material, which is available to authorized users.

K. Ludin $(\varangle) \cdot$ E. Lehmann $\cdot$ J. Kohli

Institute of Cell Biology, University of Bern,

3012 Bern, Switzerland

e-mail: katja.ludin@izb.unibern.ch

J. Mata $\cdot$ S. Watt $\cdot$ J. Bähler

Cancer Research UK Fission Yeast Functional Genomics Group,

Wellcome Trust Sanger Institute,

Hinxton, Cambridge CB10 1HH, UK

Present address:

J. Mata

Department of Biochemistry, University of Cambridge,

Cambridge CB2 1QW, UK binding peaks lay often within $2.5 \mathrm{~kb}$ of a Rec8-binding peak. Rec12 binding showed preference for large intergenic regions and was found to bind preferentially near to genes expressed strongly in meiosis. Surprisingly, Rec12 binding was also detected in centromeric core regions, which raises the intriguing possibility that Rec12 plays additional roles in meiotic chromosome dynamics.

\section{Introduction}

Homologous recombination occurs in meiosis at high levels to ensure proper chromosome segregation during the first meiotic division and to provide the basis for genetic diversity. Some regions in the genome show more recombination activity than others and are called hotspots. In Schizosaccharomyces pombe and Saccharomyces cerevisiae, meiotic recombination at hotspots and elsewhere is initiated by DNA double-strand breaks (DSBs) in one of the two homologous chromosomes (Cervantes et al. 2000; Nicolas et al. 1989), usually at a number of positions across a range of $50 \mathrm{bp}$ (Xu and Petes 1996) up to $2 \mathrm{~kb}$ (Cromie et al. 2005).

Chromatin structure can modulate the accessibility of a region for DSB formation, as shown for the histone acetylase mutant $g c n 5 \Delta$ at the meiotic recombination hotspot ade6-M26 in S. pombe (Yamada et al. 2004). Specific DNA sequences seem to have a minor role, as long as they are not required for DNA binding factors that in turn render the neighboring region accessible ( $\alpha$-hotspots). Despite high overall sequence homology $(98.6 \%)$ between the human and chimpanzee genomes, recombination hotspots, inferred by analyzing polymorphisms at orthologous loci and linkage disequilibrium, were mapped at different locations in the two species (Winckler et al. 2005). In 
addition, the recombination frequency in human female autosomes is higher than in male autosomes (Kong et al. 2002; Mohrenweiser et al. 1998). Besides the well studied $\alpha$-hotspots (Baudat and Nicolas 1997; Steiner et al. 2002), other hotspots exist, where alternative determinants render the chromatin amenable to DSB formation, e.g., nucleosome-excluding sequences ( $\beta$-hotspots; Kirkpatrick et al. 1999).

Meiotic DSBs are formed by the conserved topoisomerase II-related protein Spo11 (Rec12 in S. pombe), which works in a complex with several other proteins (Keeney 2001; Maleki et al. 2007). A Spo11 dimer forms phosphodiester links of its active site tyrosines, Y135, with the two 5 ' ends of the DSB. The subsequent, staggered endonucleolytic incision (Neale et al. 2005), presumably catalyzed by the Mre11/Rad50/Xrs2 complex and other activities, is inhibited in rad50S mutants in both yeasts (Alani et al. 1990; Cervantes et al. 2000; Young et al. 2002). This phenotype was employed in several, genome-wide analyses for Spo11-dependent DSBs in S. cerevisiae (Borde et al. 2004; Gerton et al. 2000; Mieczkowski et al. 2006). A prominent correlation of Spo11-dependent DSBs was found with high guanine-cytosine (GC) content. Correlation between recombination density and GC content was also found in the human genetic map (Yu et al. 2001), but not every hotspot displays high GC content (de Massy 2003). In accordance, an inverse correlation between preferred ATrich meiotic cohesin (Rec8) binding sites and DSB formation was reported in S. cerevisiae: Spo11 does not form DSBs in cohesin-binding regions (Glynn et al. 2004; Mieczkowski et al. 2006). Similarly, low Spo11 binding was found across budding yeast centromeres and telomeres and in regions flanking the rDNA gene cluster. The absence of Spo11 matches the hypo-recombinogenic character of these specific regions. The transposition of the centromeric region CEN3 in S. cerevisiae leads to a decrease of gene conversion and crossing over at the novel centromere (Lambie and Roeder 1986, 1988). Although meiotic DSBs inferred from covalent Spo11-DNA intermediates in rad50S strains concentrated in large chromosomal regions or were absent therein (Borde et al. 2004; Gerton et al. 2000), recent studies of meiotic DSB site distribution by monitoring resected ssDNA after Spo11 removal in dmcl-mutant strains could not completely confirm this specific pattern (Blitzblau et al. 2007; Buhler et al. 2007). DSBs were more homogenously distributed along the chromosomes and also found in pericentromeric and telomeric regions, where they were formerly reported to be absent.

In this work, we have used the chromatin immunoprecipitation (ChIP) method, firstly, to confirm Rec12 association with a meiotic recombination hotspot and, secondly, to globally map regions in the fission yeast genome where Rec12 binds. We could show that Rec12 binding agrees with recombination activity and DSB formation at a selection of Rec12-binding sites. Besides providing a map of Rec12-binding sites, we have identified a number of correlations between Rec12-binding sites and other chromosomal features.

\section{Materials and methods}

Strains, media, and general genetic methods

Tetrad dissection was described by Baur et al. (2005). Standard minimal medium, yeast extract liquid (YEL) and yeast extract agar (YEA) media, malt extract media, and the general genetic methods were described by Moreno et al. (1991). Synthetic medium (Edinburgh minimal medium [EMM]) with 2\% glucose and EMM without nitrogen source (EMM-N) with $1 \%$ glucose were described in Nurse (1975). Strains used are listed in Table 1. Rec12 was tagged at the $\mathrm{C}$ terminus with $13 m y c$ epitopes at its endogenous chromosomal locus by polymerase chain reaction (PCR)based gene targeting (Bähler et al. 1998). The resulting strain was wild type with respect to spore viability and intragenic recombination at ura $4 A$. The open reading frames (ORFs) of rec6 and recl4 were replaced by the hygromycin resistance cassette to create the deletion mutants rec6 $\Delta:: h y g^{R}$ and rec $14 \Delta:: h y g^{R}$, respectively (Hentges et al. 2005). The deletion strains showed spore viabilities less than $32 \%$, and intragenic recombination at ura $4 A$ was reduced more than 2,000-fold compared to wild type. Tagging and gene disruption constructs were confirmed by PCR and subsequent sequencing. The tagged Rec12 fusion protein was detected by Western analysis in meiotic extracts of a pat1-114 strain. Beside the auxotrophies lys4-8 (-95) and ade10-13, the following genetic markers (with respective phenotypes) were used for tetrad analysis: gpd1-E13 (no growth on YEA+1.6 M sorbitol; Ohmiya et al. 1995), rec12myc::kanR (growth on YEA+ $100 \mathrm{mg} / \mathrm{ml} \mathrm{G} 418$ ), $c d c 13-117$, clr6-1, and $c d c 3-6$ (no growth on YEA at $37^{\circ} \mathrm{C}$ ). All crosses involved two unlinked, heterozygous markers, except for sme $2 \Delta::$ ura 4 , where sme $2 \Delta::$ ura 4 ura4-D18 was crossed with ura4-D18.

\section{Chromatin immunoprecipitation}

Haploid pat1-114 strains were grown in YEL at $25^{\circ} \mathrm{C}$ to saturation $\left(\mathrm{OD}_{595}>5\right)$. The preculture was diluted into EMM and grown at $25^{\circ} \mathrm{C}$ to $\mathrm{OD}_{595}$ of 0.4 . Cells were harvested by centrifugation, washed once with one volume water, resuspended in one volume of EMM-N, and kept for at least $16 \mathrm{~h}$ at $25^{\circ} \mathrm{C}$ to arrest cells in $\mathrm{G} 1 . \mathrm{NH}_{4} \mathrm{Cl}$ was added to $0.5 \mathrm{~g} / 1$ and the temperature risen to $34^{\circ} \mathrm{C}$ to start meiosis. At various time points, 1-ml samples were taken for 4'-6- 
Table 1 S. pombe strains

\begin{tabular}{|c|c|c|}
\hline Strain & Genotype & Derivation \\
\hline KLY52 & $h^{+}$ura 4 A ura $4-D 18$ rec $12_{\text {myc }}::$ kanR pat $1-114$ & This study \\
\hline KLY59 & $h^{-}$ura $4-D 18$ rec $12_{\text {myc }}:$ kanR & This study \\
\hline KLY118 & $h^{+}$ura 4 A ura $4-D 18$ rad50S pat $1-114$ rec $12_{\text {myc }}:$ kanR & This study \\
\hline KLY108 & $h^{+}$ura $4 A-10$ ura $4-D 18$ rad50S pat $1-114$ recl $14 \Delta::$ hyg $R$ rec $12_{\text {myc }}:$ kanR & This study \\
\hline KLY123 & $h^{+}$ura 4 A ura4-D18 rad50S pat $1-114$ rec6 $4::$ hygR $\operatorname{rec} 12_{\text {myc }}:$ kanR & This study \\
\hline KLY288 & $h^{+}$gpdl-E13 & H. Aiba \\
\hline GP3718 & $h^{+}$ade6-M3049 end1-458 pat1-114 rad50S & G. Smith \\
\hline $145-5768$ & $h^{-} \operatorname{sod} 2::$ ura 4 ura $4-D 18$ & Bern \\
\hline $144-5755$ & $h^{+}$lys 3-37 ura4-D18 & Bern \\
\hline $3-97$ & $h^{-}$lys3-97 & Bern \\
\hline $4-127$ & $h^{+}$ural-61 & Bern \\
\hline $3-120$ & $h^{-}$prol-1 & Bern \\
\hline $1-15$ & $h^{+}$ade3-58 & Bern \\
\hline $3-93$ & $h^{-}$lys $1-131$ & Bern \\
\hline $2-69$ & $h^{+}$hisl-102 & Bern \\
\hline $152-6045$ & $h^{-} c d c 1-7$ & Bern \\
\hline $29-1147$ & $h^{+} c d c 1-7$ & Bern \\
\hline $3-87$ & $h^{-}$leu2-120 & Bern \\
\hline $4-150$ & $h^{+}$lys $7-2$ & Bern \\
\hline $51-2020$ & $h^{+} c d c 3-6$ & Bern \\
\hline $51-2021$ & $h^{-} c d c 3-6$ & Bern \\
\hline 29-1149 & $h^{-} c d c 13-117$ & Bern \\
\hline $3-99$ & $h^{-}$lys $4-95$ & Bern \\
\hline $3-100$ & $h^{+}$lys $4-95$ & Bern \\
\hline $15-588$ & $h^{-}$lys $4-8$ & Bern \\
\hline $15-589$ & $h^{+}$lys $4-8$ & Bern \\
\hline $27-1045$ & $h^{+}$ade10-13 & Bern \\
\hline $27-1046$ & $h^{-}$ade10-13 & Bern \\
\hline $154-6151$ & $h^{-} \operatorname{clr} 6-1$ & Bern \\
\hline $156-6226$ & $h^{+}$sme2 $\Delta::$ ura $4+$ ura $4-D 18$ & Bern \\
\hline $62-2444$ & $h^{-}$ade6-469 ura4-D18 & Bern \\
\hline
\end{tabular}

diamidino-2-phenylindole staining and 50-ml samples for ChIP. Formaldehyde solution (33.3\%, Fluka 47629) was added to a final concentration of $1 \%$, followed by incubation for $15 \mathrm{~min}$ at room temperature on a wheel. Due to massif meiotic protein degradation, we were not able to recover precipitated DNA from unfixed cells even in the presence of multiple, highly concentrated protein inhibitors. Cells were washed with one volume of cold phosphate-buffered saline (PBS; $130 \mathrm{mM} \mathrm{NaCl}, 10 \mathrm{mM}$ $\mathrm{NaPO}_{4}, \mathrm{pH}$ 7.5) and cell pellets frozen in liquid $\mathrm{N}_{2}$.

Cells were lysed in $400 \mu \mathrm{l}$ of lysing buffer [50 mM 4-(2hydroxyethyl)-1-piperazineethanesulfonic acid (HEPES) $\mathrm{pH} 7.5,140 \mathrm{mM} \mathrm{NaCl}, 1 \mathrm{mM}$ ethylenediaminetetraacetic acid (EDTA), 1\% (w/v) Triton X-100, 0.1\% (w/v) Na desoxycholate, $1 \mathrm{mM}$ Pefabloc SC, $0.5 \%(v / v)$ Pefabloc SC Protector Solution, $0.5 \%(v / v) n$-octanol, and protease inhibitor cocktail from Roche (one big tablet $/ 25 \mathrm{ml}$ buffer)] with acid-washed glass beads using the FastPrepMachine (BIO101) at level 6.5 for three cycles, $40 \mathrm{~s}$ each. Tubes were kept on ice between cycles. Crude extract was collected, and the beads were washed with $300 \mu$ l of lysing buffer. Pooled extract and wash was sonicated with a micro-tip (tapered 1/8 in.) in a Branson digital Sonifier 250 for 40 cycles at $35 \%$ amplitude (pulse on: 0.9 s, pulse off: $7 \mathrm{~s}$ ) to fragment the chromatin to an average size of $650 \mathrm{bp}$.

To obtain whole cell extracts (WCEs), the samples were centrifuged once for $5 \mathrm{~min}$, and the supernatant (SN) again for $15 \mathrm{~min}$ at $13,000 \mathrm{rpm}$ in a cold micro-centrifuge. Five hundred microliters of WCE was precipitated for $3 \mathrm{~h}$ at $4^{\circ} \mathrm{C}$ on a rotation wheel with $30 \mu$ of pre-coated magnetic beads per sample $\left(3 \times 10^{7}\right.$ Dynal M-280 beads, Sheep antimouse immunoglobulin G). The beads had been coated with $15 \mu$ monoclonal mouse anti-myc antibodies [c-myc (9E10):sc-40, from Santa Cruz] overnight at $4^{\circ} \mathrm{C}$ in PBS buffer containing $5 \mathrm{mg} / \mathrm{ml}$ bovine serum albumin. Using the MPC-E magnet (Dynal), the beads were collected, drained from solution, and washed with $1 \mathrm{ml}$ of the following buffers: twice with lysing buffer, twice with washing buffer A (50 mM HEPES pH 7.5, $500 \mathrm{mM} \mathrm{NaCl}$, $1 \mathrm{mM}$ EDTA, 1\% $[w / v]$ Triton X-100, 0.1\% [w/v] Na desoxycholate, and protease inhibitors), twice with washing buffer B (10 mM Tris-HCl pH 8.0, $250 \mathrm{mM} \mathrm{LiCl,} 1 \mathrm{mM}$ EDTA, 0.5\% [w/v] NP-40, 0.5\% [w/v] Na desoxycholate, and protease inhibitors), and once with TE (Tris-EDTA; 
$10 \mathrm{mM}$ Tris-HCl pH 8.0, $1 \mathrm{mM}$ EDTA). A $50 \mu$ elution buffer $(50 \mathrm{mM}$ Tris-HCl pH 8.0, $10 \mathrm{mM}$ EDTA, $1 \%$ $[w / v]$ SDS) was then added to the drained beads, and the precipitates were released at $65^{\circ} \mathrm{C}$ during a 10 -min incubation with occasional vortexing. After a brief centrifugation at 13,000 rpm at room temperature, the SN was transferred to a fresh tube and $150 \mu \mathrm{TE} / \mathrm{SDS}$ (10 mM Tris pH 8.0, 1 mM EDTA, $1 \%[w / v]$ SDS) was added (ChIP). Furthermore, $5 \mu \mathrm{l}$ of retained WCE was added to $195 \mu \mathrm{l}$ TE/SDS (input). After incubating both ChIP and input at $65^{\circ} \mathrm{C}$ overnight for reversal of cross-linking, proteins were digested with $1 \mathrm{mg} / \mathrm{ml}$ Proteinase $\mathrm{K}$ (Invitrogen) in TE at $50^{\circ} \mathrm{C}$ for $2 \mathrm{~h}$. After adding glycogen (final concentration of $0.4 \mathrm{mg} / \mathrm{ml}$ ), the DNA was purified by two phenol/ chloroform/isoamylalcohol extractions and one chloroform/ isoamylalcohol extraction in PGL light tubes (Eppendorf). The DNA was finely resuspended in $30 \mu \mathrm{TE}$ containing $0.05 \mathrm{mg} / \mathrm{ml}$ Rnase A (Dnase-free, QbioGene) and incubated at $37^{\circ} \mathrm{C}$ for $30 \mathrm{~min}$. DNA concentration was measured with the NanoDrop device.

\section{Real-time PCR}

Real-time PCR was carried out with AmpliTaq Gold ${ }^{\circledR}$ DNA Polymerase (TaqMan ${ }^{\circledR}$ Universal PCR Master Mix, Applied Biosystems). TaqMan probes used were RTKL1 (forward primer at a final concentration of $18 \mu \mathrm{M}$ : 5'-CAA AGTTATGGATGCTAGAGTATTTCAAAGC-3', reverse primer at a final concentration of $18 \mu \mathrm{M}$ : 5'-TCGACCGCG ACTGACAAG-3', labeled primer at final concentration of $5 \mu \mathrm{M}$ : 5'FAM-CTTGGCAATGGGATTTT-NFQ3'). The labeled primer localizes approximately $450 \mathrm{bp}$ distal to the mapped DSB site of ura4A (Gregan et al. 2005). PCR steps for the $\mathrm{ABI}$ prism 7000 were $2 \mathrm{~min}$ at $50^{\circ} \mathrm{C}, 10 \mathrm{~min}$ at $95^{\circ} \mathrm{C}$, followed by 40 cycles of $15 \mathrm{~s}$ at $95^{\circ} \mathrm{C}$, and $1 \mathrm{~min}$ at $60^{\circ} \mathrm{C}$. Duplets of $1-5 \mu \mathrm{l}(50 \mathrm{ng})$ of immunoprecipitated or input DNA were analyzed per sample. The amount of template in $1 \mu \mathrm{l}$ of input DNA was set to $100 \%$. The precipitated templates in the ChIP samples were given in percent of input.

DNA labeling, microarray hybridization, and data processing

The labeling, hybridization procedures, and data processing were described elsewhere (Heichinger et al. 2006). Two hybridizations were carried out simultaneously on both microarrays (ORF and intergenic); another two hybridizations were probed only on the intergenic microarray. In three hybridization experiments, we labeled 300 to $600 \mathrm{ng}$ immunoprecipitated DNA with Cy5 and similar amounts of input DNA with $\mathrm{Cy} 3$. In the forth experiment, we swapped the dye. The mean data of these four hybridization experi- ments were used for further calculations. Four independent control experiments with untagged Rec12 repeatedly gave no labeling of the mock-immunoprecipitated DNA sample, whereas the input DNA was labeled fine. Information on probes indicated in the text is available from a searchable Microarray Primer Database (Penkett et al. 2006). All raw data will be available from ArrayExpress. In addition, all processed data will be available from http://www.sanger.ac. uk/PostGenomics/S_pombe/. To identify Rec12 binding peaks, the sliding-window approach of the ChIPOTIe software (version 1.0) was used on the $\log _{2}$ values of the average of two (ORF probes) or four (intergenic probes) Rec12-binding ratios with a sliding window of 1,000 and $250 \mathrm{bp}$ steps. Prism software version 4.0 was used for calculations of correlation tests.

The transformation of the Affimetrix data set (meiotic cohesin binding, see Ding et al. 2006) to our intergenic and ORF chip architecture was done by location of the Affimetrix oligos by sequence (http://chromosomedynamics.bio.titech. ac.jp/download/pombe_chip/pombe_chip.html) and assigning the Rec8 to input ratio from the 250-bp window given in Ding et al. (2006) for the wild type to every oligo. These values, assigned to the sequence, were then used for calculation of the average over the length of our intergenic and ORF probes.

\section{DSB Southern}

From a meiotic pat1-114 rad50S time course, $5 \times 10^{8}$ cells were harvested at appropriate time points (T0, T2, T3, T4, T5, T6), washed with $50 \mathrm{mM}$ EDTA $\mathrm{pH} 8.0$, and resuspended in $300 \mu \mathrm{l}$ SpheroBuffer $(0.4 \mathrm{M}$ EDTA, $10 \mathrm{mM} \mathrm{NaN}_{3}, 5 \mathrm{mM}$ dithiothreitol, $1 \mathrm{mg} / \mathrm{ml}$ zymolyase [Seikagaku 120493], $5 \mathrm{mg} / \mathrm{ml}$ lysing enzyme [Sigma L1412], and embedded in low melting-point agarose to a final concentration of $1 \%$ ). Cells in agarose plugs were lysed in $1.8-\mathrm{ml}$ SpheroBuffer at $37^{\circ} \mathrm{C}$ for $1 \mathrm{~h}$, proteins were digested once in $1.8 \mathrm{ml}$ NDS/PK (0.5 M EDTA, $10 \mathrm{mM}$ Tris pH 7.5, $10 \mathrm{mM} \mathrm{NaN}_{3}, 1 \% \mathrm{Na}$ lauryl sarcosine, $1 \mathrm{mg} / \mathrm{ml}$ Proteinase $\mathrm{K})$ at $50^{\circ} \mathrm{C}$ overnight and again in $1.8 \mathrm{ml} \mathrm{SDS} / \mathrm{PK}$ (0.5 M EDTA, $10 \mathrm{mM}$ Tris $\mathrm{pH} 7.5,0.5 \%$ SDS, $1 \mathrm{mg} / \mathrm{ml}$ Proteinase $\mathrm{K}$ ) at $50^{\circ} \mathrm{C}$ overnight. Plugs were extensively washed with TE containing $1 \mathrm{mM}$ phenylmethylsulfonyl fluoride, exchanging the buffer several times, at room temperature and stored afterward in TE at $4^{\circ} \mathrm{C}$.

Genomic DNA embedded in agarose plugs was digested in the appropriate buffers with restriction enzymes according to the supplier (NEB). In particular, in $200 \mu \mathrm{l}$ final volume, 100 units of $\mathrm{ClaI}$ were used at $37^{\circ} \mathrm{C}$ overnight. Melted agarose plugs were loaded on a $0.8 \%$ Tris-borateEDTA $(90 \mathrm{mM}$ Tris base, $90 \mathrm{mM}$ boric acid [pH 8.3], $2 \mathrm{mM} \mathrm{Na} \mathrm{EDTA}_{2}$ ) agarose gel and run overnight in the cold 
room. After ethidium bromide staining, the DNA was blotted on GeneScreenPlus membrane (PerkinElmer) with the VacuGeneXL device (Pharmacia), according to the manufacturer. Radioactive probes were made by random priming of gel-purified PCR fragments with $\left[\alpha-{ }^{32} \mathrm{P}\right] \mathrm{dCTP}$ using the Ready-To-Go DNA Labeling Beads (Amersham). Hybridization and membrane washing procedures were done according to the membrane supplier. Parental and DSB bands were detected by a phosphoimager and quantified with the AIDA software (Raytest, Germany). DSB bands were related to the parental band (100\%) after background subtraction of the same area in the T0 time sample lane.

\section{Results}

Rec12 associates with the meiotic DNA break region at the $u r a 4 A$ hotspot

Point mutations in the $5^{\prime}$ region of the ura $4 A$ gene displayed gene conversion frequencies of $18 \%$, whereas in the $3^{\prime}$ region, only $6 \%$ were detected (Baur et al. 2005). This conversion gradient was explained by initiation of recombination in the $5^{\prime}$ upstream region of $u r a 4 A$ by DSB formation. A meiotic DSB site has been detected and mapped approximately $500 \mathrm{bp}$ upstream of the ura $4 \mathrm{~A}$ translation start codon (Gregan et al. 2005; Sakem 2005).

To find out, whether Rec12 associates with sequences in the DSB formation region of ura4A, we employed ChIP with a functional, C-terminal myc-tagged Rec12 in a rad50S mutant. The experiments were carried out by induction of meiosis in haploid pat1-114 mutant strains with the advantage of high synchronicity (Beach et al. 1985). pat1-114 meiosis shows a chromosome segregation defect in the first meiotic division (Yamamoto and Hiraoka 2003), but has been used systematically for the timing of early meiotic events including DSB formation (Cervantes et al. 2000; Young et al. 2002). In addition, our strains carried the rad50S mutation in which DSBs remain un-resected (Young et al. 2002). Rec12myc-DNA complexes fixed by formaldehyde were purified from meiotic cells by immunoprecipitation using an anti-myc antibody. Precipitated DNA was tested for ura $4 A$ sequences by real time PCR (Fig. 1). Coincident with DSB formation, the association of Rec12 with ura4A was found to increase from the time point $0 \mathrm{~h}(1.6 \%)$ to $4 \mathrm{~h}(9 \%)$.

Strains with rec $14 \Delta$ or rec $6 \Delta$ deletions showed a strong decrease in meiotic recombination (Evans et al. 1997), and a rec14 mutant had the same altered linear elements as a rec12 mutant (Molnar et al. 2003). No more ura $4 A$ hotspot sequences were precipitated in rec $14 \Delta$ and rec $6 \Delta$ strains than in a rec${ }^{+}$strain with untagged Rec12 (Fig. 1b), a

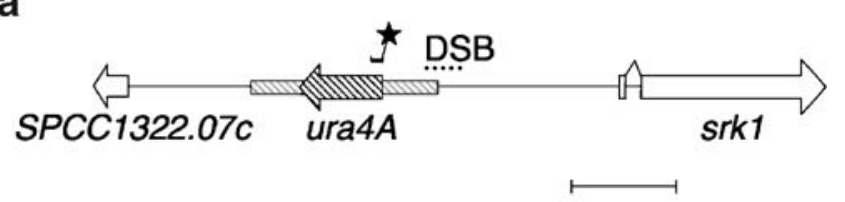

b

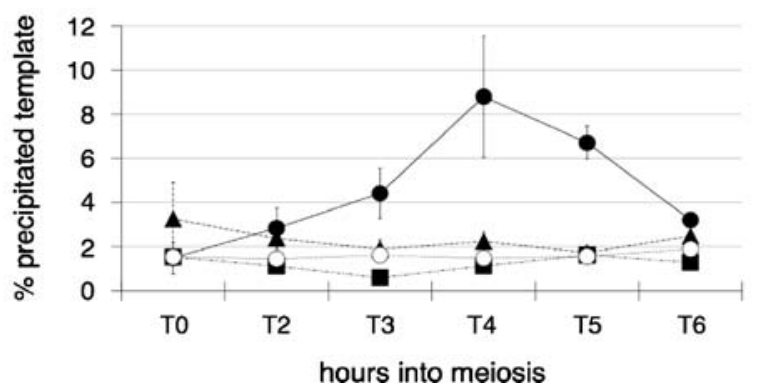

Fig. 1 Rec12 binds to ura $4 A$ hotspot sequences a Map of the ura $4 A$ insertion used for real-time PCR detection of Rec12-binding sequences. ORFs are given as horizontal arrow boxes. The 1.8-kb Hin D III ura4 fragment (Grimm et al. 1988), inserted between SPCC1322.07c and $s r k 1$, is cross-hatched. Dots indicate the region of DSB formation (Gregan et al. 2005). The location of the $\operatorname{ura} 4 A$ TaqMan ${ }^{\mathbb{B}}$ probe is given by a small bar with an asterisk. The length of the scale bar is $1 \mathrm{~kb}$. b Graph showing the ratio of real-time PCR product from immunoprecipitated chromatin versus total chromatin in rec12myc rad50S (filled circle), rec14 4 rec $12 m y c$ rad50S (filled triangle), rec6 $\Delta$ recl2myc rad50S (filled square), and rad50S rec12+ (open circle) strains, during meiotic progression in a haploid pat1-114 strain. Independent experiments were performed four times for wild type, three times for recl $4 \Delta$, and twice for rec $6 \Delta$. Experiments with the untagged control strain were repeated twice. The $y$-axis gives the ratio of real time template of immunoprecipitated sample to input sample, normalized to $1-\mu 1$ input, which was set to $100 \%$ (see "Material and methods"). Error bars indicate the standard error of the mean (SEM)

indicating a requirement of Rec14 and Rec6 for formation of DSBs.

\section{Global analysis of Rec12 binding}

The capability of Rec12myc to associate with ura4A hotspot sequences prompted us to precipitate Rec12mycDNA sequences from total chromatin to construct a genomic Rec12-binding map by hybridization to DNA microarrays. The microarrays covered all coding and noncoding regions of the $S$. pombe genome on probes of 180 500 bp (ORF array; Lyne et al. 2003) and 36-2,900 bp (intergenic array; Heichinger et al. 2006). Rec12myc immunoprecipitated DNA as well as input DNA from time point $4 \mathrm{~h}$ were differentially labeled and hybridized simultaneously to the microarrays. The Rec12-binding ratio was defined as the coefficient of the amount of immunoprecipitated DNA to input DNA on each probe. Data for the left arm of chromosome II from four independent hybridization experiments are shown in Fig. 2. To single out significant Rec12-binding peaks, the ChIPOTIe sliding average algorithm for uniformly arranged data was applied 


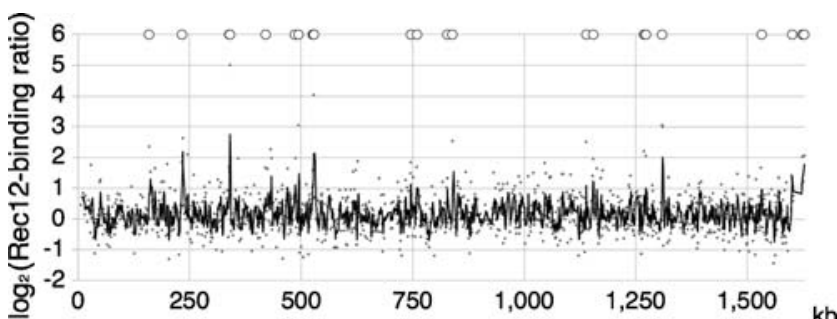

Fig. 2 Mapping of Rec12 binding on the left arm of chromosome II on the $x$-axis, the left telomere is given at $0 \mathrm{~kb}$, the centromere at $1,600 \mathrm{~kb}$. Microarray signal ratios of Rec12 enrichment relative to input were plotted for each probe against chromosome position and are given in a $\log _{2}$ scale as the mean of 2 (ORF sequences) or 4 (intergenic sequences) independent experiments (small gray dots). The black line indicates a moving average curve over three values $(\sim 3.3 \mathrm{~kb})$. The Rec12-binding peaks determined by the CHIPOTIe algorithm are indicated above the curve $(\mathrm{O})$

(Buck et al. 2005). In this way, 144 Rec12-binding peaks were identified genome-wide (Table S1; Fig. 2).

DSB formation near a Rec12-binding peak

To check for DSB formation near a strong Rec12-binding peak, SPBC1685.13 on chromosome II (Rec12-binding ratio on probe chr2.187.1>16, Table S1), Cla I digested genomic DNA from time course samples of haploid pat1114 rad50S meiosis was analyzed using Southern hybridization (Fig. 3). Three meiosis-specific bands could be detected at $4 \mathrm{~h}$ into meiosis, and the sum was calculated to be $5.6 \%$ compared to the parental $\mathrm{Cla}$ I band. Thus, at sites where meiotic DSBs are formed, high level of Rec12 binding is found on a nearby probe.
Hotspots of recombination localize to sites with high Rec12 binding

To correlate Rec12 binding with recombination activity, probes with various Rec12-binding ratios were checked for nearby genetic markers. Among eight markers with considerably high Rec12-binding ratios on neighboring probes, there were two CHIPOTIe Rec12-binding peaks, chr2.1694.1 and chr2.103.1 (Table S1). From crosses of various combinations of heteroallelic markers, tetrads were dissected (Table 2) and the spore clones analyzed for the respective phenotypes ("Material and methods"). Gene conversion frequencies ranging from $1 \%$ to $16.7 \%$ clearly exceeded the average non-Mendelian-segregation (NMS) frequency of $0.28 \%$ for all studied genes (Gygax and Thuriaux 1984; Munz 1994), and for six markers, the values were even higher than the value for the well-studied meiotic recombination hotspot ade6-M26 (5.1\%; Gutz 1971).

Rec12 binding and crossover on chromosome I

Genetic distance between two linked markers is a function of the number of crossovers in the interval. As crossover is one way to resolve recombination intermediates initiated at Rec12-dependent DSBs, a positive correlation between Rec12 binding and genetic distance would be expected. We used a set of different markers, which map across chromosome I (Fig. S2), and measured intergenic recombination in the intervals (Table S2). The genetic distance $(\mathrm{cM} / \mathrm{kb})$ was compared with the sum of Rec12-binding ratios, which was adjusted to the sum of the probe lengths in the interval. The two sets of data were strongly correlated

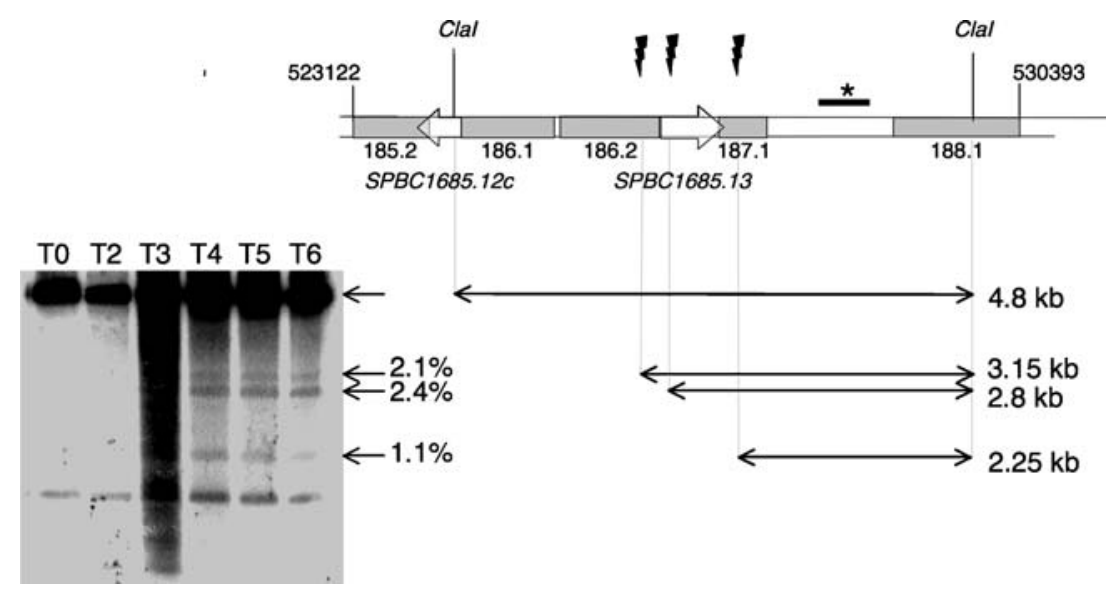

Fig. 3 Meiotic DSBs appear at a Rec12-binding peak. A Southern blot of Cla I digested genomic DNA from a pat1-114 meiotic time course is shown. Above the autoradiogram, hours into meiosis are indicated. The arrows on the right side indicate meiosis-specific DSB fragments and their quantification with respect to the parental Cla I fragment. The non-meiosis-specific band below may arise from a cross-hybridization. Such bands were also observed at other loci
(Cromie et al. 2006). The sketch on the right gives the chromosomal location of the three meiosis-specific DSBs on chromosome II (bolts). The arrowed (ORF) and gray (intergenic) boxes give the corresponding probes on the microarrays, together with the probe names. The bar with an asterisk indicates the location of the radioactive probe 
Table 2 Increased gene conversion frequencies near Rec12-binding sites

\begin{tabular}{|c|c|c|c|c|c|c|c|}
\hline \multirow[t]{2}{*}{ Rec12-binding ratio ${ }^{\mathrm{a}}$ (probe) } & \multirow[t]{2}{*}{ Marker } & \multirow[t]{2}{*}{ Chromosome } & \multicolumn{3}{|c|}{ Conversions } & \multirow[t]{2}{*}{ Tetrads analyzed } & \multirow[t]{2}{*}{ Conversion frequency $(\%)$} \\
\hline & & & $3+: 1-$ & $1+: 3-$ & $4+: 0_{-}^{-}$ & & \\
\hline $32.1(\operatorname{chr} 2.103 .1)$ & sme2 $\Delta::$ ura 4 & II & 0 & 1 & 0 & 100 & 1.0 \\
\hline $30.1(\operatorname{chr} 2.1694 .1)$ & gpd1-E13 & II & 11 & 0 & $1^{\mathrm{b}}$ & 108 & 12.0 \\
\hline $3.6(\operatorname{chr} 1.759 .1)$ & $\operatorname{rec} 12_{\text {myc }}: \because k a n R$ & $\mathrm{I}$ & 13 & 5 & 0 & 108 & 16.7 \\
\hline $3.1(\operatorname{chr} 2.139 .1)$ & $c d c 13-117$ & II & 11 & 7 & 0 & 220 & 8.2 \\
\hline $2.5(S P B C 1105.02 c)$ & $\operatorname{lys} 4-8$ & II & 2 & 11 & 0 & 207 & 6.3 \\
\hline $2.5(S P B C 1105.02 c)$ & lys $4-95$ & II & 1 & 6 & 0 & 56 & 12.5 \\
\hline $2.3($ chr2.310.1) & clr6-1 & II & 3 & 0 & 0 & 37 & 8.1 \\
\hline $2.1(\operatorname{chr} 1.1107 .1)$ & $c d c 3-6$ & I & 8 & 10 & 0 & 141 & 12.8 \\
\hline $1.4(\operatorname{chr} 3.475 .1)$ & ade10-13 & III & 0 & 2 & 0 & 135 & 1.5 \\
\hline
\end{tabular}

${ }^{\text {a }}$ Average Rec12-binding ratio of four (intergenic probes) or two (ORF probes) experiments.

${ }^{\mathrm{b}}$ One tetrad with two conversion events was found and counted twice.

(Pearson coefficient $=0.94, p$ value $=0.0002$ ). Figure 4 shows the correlation plot with a simple linear regression fit. The sum of background binding due to unspecific DNA precipitation with the antibody over the long intervals could be responsible for such a positive correlation, although no background binding was detected in control experiments with untagged Rec12 ("Material and methods"). To test whether the correlation depends on background binding, the Rec12-binding ratios were randomly redistributed over chromosome I and added up again in the same intervals (Table S3). Less than $5 \%$ of the randomizations showed Pearson correlation $p$ values lower than the observed $p$ value. If the correlation would be a consequence of background binding, more randomizations with $p$ values similar to the observed $p$ value would be expected. We conclude that the amount of Rec12 binding per unit DNA length is not evenly distributed along chromosome I and that high Rec12 binding is associated with increased recombination.

Distribution of Rec12-binding peaks with respect to chromosomes, large intergenic regions, non-protein coding genes, and centromeres

From the 144 CHIPOTIe Rec12-binding peaks (Table S1), 69 were on chromosome I, 44 on chromosome II, and 31 on chromosome III. If the hotspots would be evenly distributed, one would expect less hotspots on chromosomes I and III (64 and 28) but more on chromosome II (52). However, the observed distribution is not significantly different from the expected one $\left(\chi^{2}=1.01, p=0.6\right)$. Surprisingly, the average Rec12-binding ratio on chromosome II (1.24) is higher than on chromosome I (1.18) and III (1.16, see Table S4). Nevertheless, the ratio of genetic length versus physical length is the same on chromosomes I and II $(0.17 \mathrm{cM} / \mathrm{kb})$ and higher on chromosome III (0.22 cM/kb; Munz 1994). The higher average Rec12-binding ratio and the lower numbers of Rec12-binding peaks may reflect more evenly distributed
Rec12 on chromosome II than on the other chromosomes. Extended "cold" or "hot" regions were not detected.

The major meiotic DSB sites $m b s 1$ and $m b s 2$ localize to so-called "gene-free regions" (Cromie et al. 2005). These 4to $8-\mathrm{kb}$ long sequences occur on all three chromosomes (Wood et al. 2002). They display significant deviations from the average nucleotide composition of the whole genome, are sometimes accompanied by repetitions of oligonucleotides (low complexity), and are often associated with $(G-C) /(G+C)$ strand switches (Lobry 1996), where a region with prominent $(G)$ content is followed by a region of similar size with prominent $(C)$ content. Besides the 51 low-complexity gene-free regions, another 21 gene-free regions of similar size lacking low complexity exist. Seventeen out of the 144 CHIPOTIe Rec12-binding peaks fall into gene-free regions (Table S1), among them $m b s 2$ (measured on probe chr1.279.2) with a Rec12-binding ratio of 4. Comparison of the total length of all large gene-free

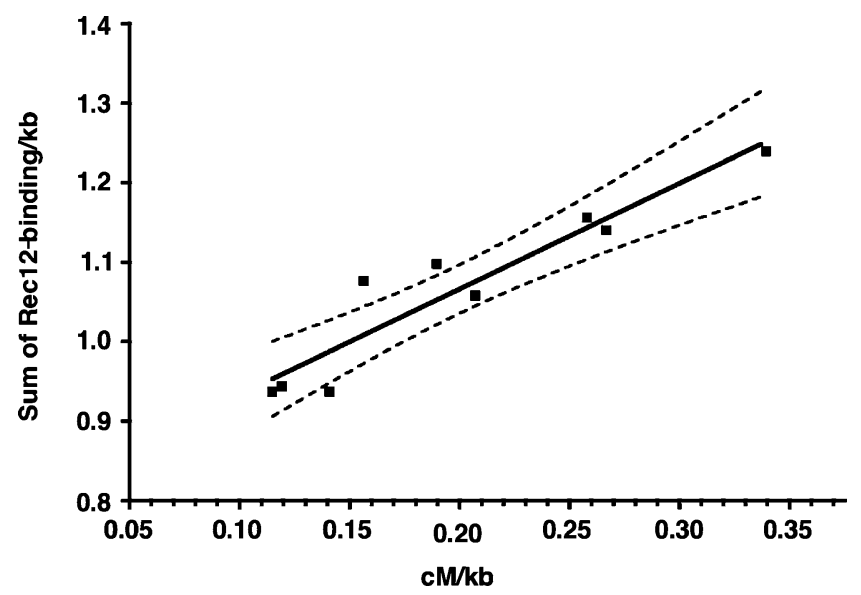

Fig. 4 Rec12 binding correlates with crossovers. Correlation plot of genetic distance in $\mathrm{cM} / \mathrm{kb}$ measured in intervals along chromosome I (see Table S2) versus the sum of the Rec12-binding ratios in the same intervals divided by the sum of probe lengths. The linear correlation line (solid line) is given together with its $99 \%$ confidence limit (dashed lines) 
region probes $(280.5 \mathrm{~kb})$ with the total length of all measured probes $(12,064 \mathrm{~kb})$ leads to an expectation of only 3 hotspots. Thus, Rec12 clearly shows a preference to bind in large gene-free regions. The Rec12-binding ratios on probes within gene-free regions had a higher average value (1.54) compared to the average value of all probes in intergenic regions (1.21, Fig. 5). The effect was most prominent on chromosome I, although two large gene-free regions had low Rec12-binding ratios (data not shown). The same trend was detected on chromosomes II and III, but with overlapping standard errors (Fig. 5).

Thirteen Rec12-binding peaks were found near nonprotein coding genes (see Table S1). These genes are transcribed into poly (A)-bearing RNAs but lack long ORFs. Based on the total length of all annotated nonprotein coding genes $(185 \mathrm{~kb})$, only two Rec12-binding peaks were expected. The average of Rec12 binding to probes covering annotated non-protein coding genes $(1.59 \pm$ $0.24)$ was higher than the average of all probes $(1.20 \pm$ 0.01 ). It has been pointed out, that non-protein coding genes often map to intergenic regions longer than $2.4 \mathrm{~kb}$, and $20 \%$ of them are in large gene-free regions (Watanabe et al. 2002). Out of the 17 large gene-free regions with a Rec12-binding peak, only four contain an annotated nonprotein coding gene (24\%). Thus, the Rec12-binding correlations with large gene-free regions and non-protein coding genes may be independent. Alternatively, there may be so far undetected non-protein coding genes in large gene-free regions. It has been extrapolated that about 300 such genes remain to be discovered (Watanabe et al. 2002).

Recombination across centromere II was reported to be low (Nakaseko et al. 1986). Unexpectedly, strong Rec12 binding was detected at the inner core and inner repeats of all three centromeres (Fig. 6). The ChIPOTIe algorithm captured these sites as Rec12-binding peaks (Table S1).

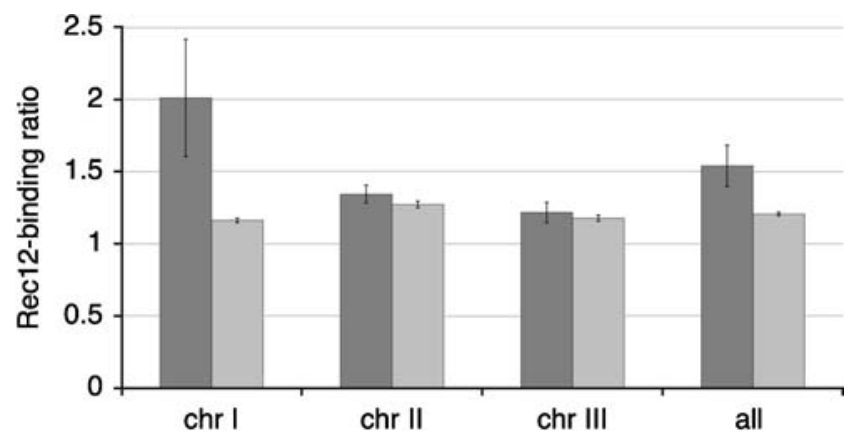

Fig. 5 Rec12 binds to large gene-free regions particularly on chromosome I. The average Rec12-binding ratio for the probes in large gene-free regions (dark bars) versus the average for all probes in intergenic regions (light bars) is shown. The ratios are given for the three chromosomes separately and globally (on the right). The bars indicate the standard error of the mean. Large gene-free regions of the three chromosomes do not vary in length (classes of increasing $1,000 \mathrm{bp}$ steps from 2,000 to $9,000 \mathrm{bp}, \chi^{2}=20.6, p=0.1$ in $95 \%$ confidence interval)
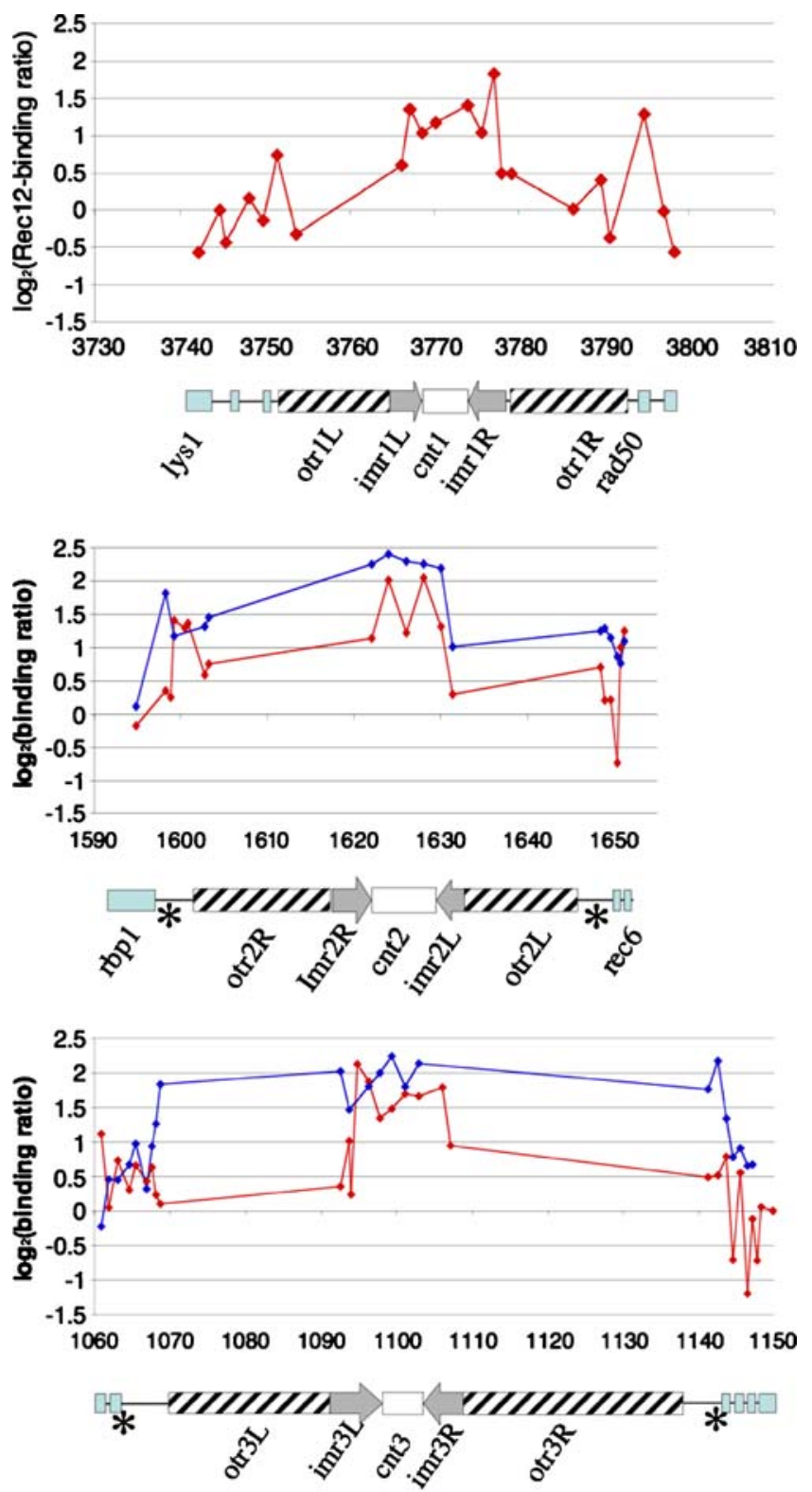

Fig. 6 Rec12-and Rec8 binding in centromere regions. The averaged Rec12-binding ratios (red dots) from four experiments (intergenic probes) or two experiments (ORF probes) and the transformed Rec8binding ratios (blue dots) from the Hiraoka laboratory (Ding et al. 2006) are plotted against chromosomal location. The units on the $x$ axis are in kilobase and scaled from the left chromosome ends; the centromere structures are depicted below. Light blue boxes indicate ORF probes, cross-hatched boxes the outer repeats, light gray arrows the inverted inner repeats, asterisks tRNA clusters, and white boxes the core regions. Rec12-binding peaks in centromere I are found in imr1L (chr1.1605.1, see Table S1), in cnt1 (chr1.1605.3), and in imr1R (chr1.1607.2); in centromere II in cnt2 (chr2.651.2 and chr2.651.4); in centromere III in imr3L (chr3.535.1), in cnt3 (chr3.531.1 and chr3.537.2), and in $i m r 3 R$ (chr3.538.2) 
Inverse correlation of Rec12-binding with GC content and origins of replication

Local high GC content correlates with high Spo11 binding in $S$. cerevisiae on a microarray with ORF probes (Gerton et al. 2000), and the third codon position GC content further increases this correlation (Birdsell 2002). We thus calculated the GC content of every ORF and intergenic probe on the microarrays. A Spearman statistical test showed a significant inverse correlation between Rec12binding ratio and $\mathrm{GC}$ content in both intergenic and ORF sequences (Table 3, Fig. S3a).

The inverse correlation between GC content and Rec12 binding suggests that Rec12 binds preferentially in AT-rich regions. AT-rich islands were proposed to act as origins of replication (Segurado et al. 2003). Early replication forks in meiotic S-phase, stalled by hydroxyurea, which inhibits ribonucleotide reductase and thus depletes the nucleotide pools, were recently mapped on the same ORF and intergenic microarray platforms (Heichinger et al. 2006). A Spearman statistical test revealed a significant inverse correlation between Rec12-binding ratios and meiotic origins of replication (Table 3). Examples of this inverse correlation are shown across a $250-\mathrm{kb}$ region on chromosome II in Fig. S3b.

Rec12-binding correlates with gene expression and cohesin binding

Transcription during meiosis might render chromatin in promoter regions accessible to Rec12. We therefore asked whether genes whose transcription is induced during meiosis were also preferred sites for Rec12 binding. Genome-wide transcription of a pat1-114 strain at $4 \mathrm{~h}$ (Mata et al. 2002) was significantly correlated with the Rec12-binding ratio on the ORF sequences (Table 3). The correlation was most prominent for genes with high induction factors. Out of the ten most strongly induced genes, seven were also found by the CHIPOTIe algorithm as Rec12-binding peaks (C29A10.02, meu10, meu $3 R C$, $d m c 1$, meu4, meu19, and C22H10.13).

It was proposed for $S$. cerevisiae that Spo11-binding peaks may represent regions where initiation of recombination was not prevented by cohesin binding (Glynn et al. 2004; Mieczkowski et al. 2006). We therefore compared Rec12 binding with published data on Rec 8 binding in pat 1114 haploid meiosis across chromosome II and a part of chromosome III (Ding et al. 2006). For this purpose, the Rec8-data were transformed to our microarray architecture (see "Material and methods"). Unexpectedly, a significantly positive correlation was evident (Table 3). A 250-kb region of chromosome II is shown in Fig. S3c. Notably, Rec12binding peaks on chromosome II did not overlap with Rec8binding peaks on the same probe (Table S1). Moreover, no overlap was detected for probes with a Rec12-binding ratio $\left(\log _{2}\right)>1$ (Table S5). But, when the limit was $>0.8$, a positive correlation could be detected, suggesting that the Rec8binding peaks might be at the edges of the Rec12-binding peaks. In fact, of the 43 designated Rec12-binding peaks on chromosome II (excluding peaks in centromere II), 27 had a nearby Rec8-binding peak [Rec8-binding ratio $\left(\log _{2}\right)>0.5$ ] within $2,500 \mathrm{bp}$ on either side. In other words, $62.8 \%$ of the Rec12-binding peaks on the arms of chromosome II had a Rec8-binding peak at a distance $<2,500 \mathrm{bp}$. To test for significance, we calculated how many Rec8-binding peaks fall into random 5,000 bp windows, assuming a Rec8binding peak width of $3,000 \mathrm{bp}$ and a peak height of 0.5 (Table S6). Under this scenario, only $47.8 \%$ of the $5,000 \mathrm{bp}$ windows could expect a hit, less than the $62.8 \%$ determined above. The average distance of the 27 Rec12-binding peaks to nearby Rec8-binding peaks was $1.7 \mathrm{~kb}$, with a range of 55 to 2,400 bp (Fig. S4). However, due to different resolutions of the two microarrays (average probe length in Rec12binding microarrays: 1,100 bp/probe, Rec8-binding microarray: $250 \mathrm{bp} /$ probe), we cannot rule out co-localization for the smaller distances measured. At the centromeres of

Table 3 Correlation of Rec12-binding ratios with specific chromosomal features

\begin{tabular}{|c|c|c|}
\hline Correlation of Rec12 binding with data set, applied probes on microarray (number of pairs analyzed) & $p$ value & Spearman $r$ \\
\hline GC content, intergenic probes $(6020)^{\mathrm{a}}$ & $<0.0001$ & -0.10 \\
\hline GC content, ORF probes (4927) & $<0.0001$ & -0.16 \\
\hline GC content, intergenic and ORF probes (10947) & $<0.0001$ & -0.15 \\
\hline Meiotic replication origins, intergenic and ORF probes $(8847)^{\mathrm{b}}$ & $<0.0001$ & -0.06 \\
\hline Meiotic transcription, ORF probes $(4685)^{\mathrm{c}}$ & $<0.0001$ & 0.09 \\
\hline Rec 8 binding, intergenic and ORF probes $(5000)^{\mathrm{d}}$ & $<0.0001$ & 0.18 \\
\hline
\end{tabular}


chromosome II and III, co-localization of Rec12 binding and Rec 8 binding was prominent. Among 20 probes of the inner repeats and the core regions (Fig. 6), we found a high correlation between Rec12- and Rec8 binding (Spearman $r=$ $0.58, p$ value $<0.0018$ ). No correlation was found in 21 probes of the mating type region.

\section{Discussion}

Association of Rec12 with ura $4 A$ hotspot sequences

To test whether Rec12 associates with DNA sequences of a meiotic recombination hotspot, we checked Rec12 immunoprecipitated DNA from a meiotic time course by realtime PCR to ura4A sequences (Fig. 1). Experiments in a $\operatorname{rad} 50^{+}$strain showed only a slight enrichment of precipitated $u r a 4 A$ sequences at $4 \mathrm{~h}$ (Fig. S1), which can be explained by removal of Rec12 and subsequent repair of DSBs. In rad50S mutant strains, however, the amount of precipitated $u r a 4 A$ sequences at $4 \mathrm{~h}$ was in the range of the amount of broken DNA (4-9\%) at this DSB site measured by Southern blot experiments at $4 \mathrm{~h}$ in haploid pat1-114 rad50S meiosis (Gregan et al. 2005). The low values at late time points were not expected, as meiotic DSBs persist in rad50S mutants. This drop of hotspot sequence recovery may be due to degradation of the Rec 12 protein in the extracts. As the immunoprecipitation was done after in vivo formaldehyde cross-linking, the values at 2 and $3 \mathrm{~h}$ may indicate that Rec12 already binds before or during DNA replication, although DSB formation is not detected at these times (Gregan et al. 2005). Rec7, the S. pombe homolog of the initiation complex member Rec114 in $S$. cerevisiae, and the meiotic cohesin subunit Rec8 are expressed upon nitrogen starvation before the onset of DNA replication (Grishchuk 2003; Molnar et al. 2001; Parisi et al. 1999). In addition, mutants of components of the DSB formation complex advance the start of meiotic S-phase, which suggests a role before DNA synthesis (Doll 2005). Rec12myc was not proficient to precipitate ura $4 A$ hotspot sequences in the recombination deficient rec $6 \Delta$ or rec $14 \Delta$ mutants. There are no Rec6 sequence homologues in other organisms, but a requirement of the Sordaria macrospora Rec14 homologue, Ski8, to localize Spo11 to chromosomes in meiotic prophase was also found (Tesse et al. 2003). In S. cerevisiae, however, Spo11 association with hotspot sequences was independent of the Rec14 homolog Ski8 (Prieler et al. 2005).

Rec12-binding peaks and DSB formation

We used a sliding window algorithm to identify peaks of Rec12-binding ratios from the Rec12-Chip on CHIP data, which was not otherwise filtered. The known site of strong
DSB formation $m b s 2$ (Cromie et al. 2005) was detected as a Rec12-binding peak (probe chr1.279.2, Table S1), but the mbs 1 and ura $4 A$ hotspots were not among the 144 Rec12binding peaks due to lack of data from nearby probes. However, at both sites, considerable Rec12 binding was detected (2.2 for probe chr1.316.1 at $m b s 1$ and 2.5 for probe chr3.40.1 $5^{\prime}$ to ura4). In addition, 8 out of 11 major DSB sites on the $1,105 \mathrm{~kb}$ Not I fragment of chromosome I (Cromie et al. 2007) coincide with Rec12-binding ratios of more than two, although only two of the CHIPOTIe Rec12binding peaks were found among them. The criteria set for peak scoring by the ChIPOTIe algorithm were obviously rigorous. We can conclude from this accordance that a good part of Rec12 binding comes from covalent Rec12-DNA interactions.

Rec12 binding correlates with meiotic recombination activity

Repair of meiotic DSBs can engage the sister chromatide or the homolog. If the latter is involved, repair results in a gene conversion event in the vicinity of the DSB site and/or leads to a reciprocal exchange of the involved homologs. As Rec12 is responsible for meiotic DSBs, Rec12-binding peaks are expected to correlate with recombination activity.

High gene conversion frequencies go along with high Rec12 binding, but no quantitative relationship (Table 2) can be deduced from the tetrad analysis results. We neither know the location of DSBs nor the position of the used markers nor the steepness of conversion gradients. However, five of these Rec12-binding sites, chr2.103.1, chr1.759.1, chr2.139.1, SPBC1105.02c, and chr2.310.1, show considerable Rec12-DNA linkage (Cromie et al. 2007). The remaining two sites have either a low Rec12binding ratio (chr3.475.1) or show a shifted Rec12-DNA linkage peak (chr2.1694.1), which might be due to strain differences. The marker sme $2 \Delta::$ ura 4 with the lowest gene conversion frequency but the highest Rec12-binding ratio (32.1) of the eight markers is a peculiar exception. The sme 2 gene encodes a meiosis-essential non-coding RNA, called meiRNA, with whom the Mei2 protein forms a dotlike structure in the nucleus at the sme2 locus during prophase (Shimada et al. 2003). High Rec12 binding with a considerably low gene conversion frequency at this site may indicate that repair of DSBs involves mostly the sister chromatid at this site. Alternatively, Rec12 binding at sme2 may serve also for another function than DSB formation (see below paragraph on centromeres).

Genetic distance on chromosome I correlates with Rec12 binding (Fig. 4). Gene conversion events without accompanying crossover (13\% to $36 \%$ depending on the locus; Cromie et al. 2005) could explain the positive $y$-intercept of the linear regression line because such conversion events do 
not contribute to genetic distance. In addition, Rec12 binding leading to DSB repair by interaction with the sister chromatid may also contribute to the positive $y$-intercept. The formation of Holliday junction intermediates occurs more frequently between sisters than homologous chromatids in S. pombe (Cromie et al. 2006). Such DSBs would be scored in Southern blots, but their repair would not result in crossovers or gene conversions. Overall, a good part of the Rec12 binding reflects recombination activity as observed by correlation with DSB formation, gene conversion, and crossover frequencies. In addition, there are no gross differences between regions with respect to Rec12 binding in rad50S strains as it was reported for S. cerevisiae Spo11 (Gerton et al. 2000). Recently, alternative studies in $S$. cerevisiae RAD50 wild-type background indicate, however, that this specific pattern could be attributed to the rad50S mutant (Blitzblau et al. 2007; Buhler et al. 2007).

Correlation of strong Rec12 binding with chromosomal features

Previously, meiotic hotspots of DSB formation have been reported in large intergenic regions (Cromie et al. 2005). The high representation of Rec12-binding peaks in these regions confirms this finding. It is not obvious why the Rec12-binding pattern with respect to large gene-free regions differs for chromosome I (Fig. 5). It neither has significantly more large gene-free regions than the other chromosomes $\left(\chi^{2}=2.5, p=0.3\right)$ nor do they significantly differ in size (see legend to Fig. 5). This finding contrasts the situation in budding yeast and could reflect differences of intergenic region lengths between the two yeast genomes (Wood et al. 2002).

Contrary to the correlation of GC content with covalent Spo11-DNA association in S. cerevisiae (Gerton et al. 2000), we find that Rec12 binding shows an inverse correlation to GC content. A similar relationship was reported in Arabidopsis thaliana where crossover rates from chromosome 4 inversely correlated with GC content (Drouaud et al. 2006). In addition, in the human MHC class II region, only one out of three crossover clusters corresponded to a region of higher than average GC content (de Massy 2003). Thus, the relationship between GC content and recombination hotspots does not seem to be the same in all eukaryotes. Although replication origins and Rec12-binding sites prefer AT-rich gene-free regions, they exclude each other, which would be consistent with an early loading of the DSB initiation complex before or during S-phase, as discussed above.

Promotors of genes with strong transcription during meiotic prophase are more likely to be targets of Rec 12 binding. Whether this correlation is due to specific transcription-factor binding remains to be elucidated.
However, it has been shown that transcription-factor binding can promote recombination activity, but is not sufficient for high recombination at all transcription-factor binding sites in a given region (Kon et al. 1997; Mieczkowski et al. 2006; Steiner and Smith 2005).

\section{Rec12 binding at centromeres}

Rec12-binding peaks were detected in all three centromeric core regions (Table S1, Fig. 6). Cromie et al. (2007) showed recently a strong correlation between DSB formation and Rec12 chromatin immunoprecipitated DNA (Rec12 covalently bound to DNA, no formaldehyde crosslinking) in a rad50S mutant on a genome-wide scale. They found no Rec12-DNA linkage in the centromeres. Thus, we have to assume that the detected Rec12-binding peaks in the centromere are the result of DSB-independent association. Alternatively, the absence of putative DSBs in the centromere might be an artifact of the rad50S mutant. DSBs might be resected (and repaired) through an alternative mechanism, thus escaping the rad50S trap. In budding yeast, a role of Spo11 in early chromosome pairing and determination of S-phase length was demonstrated (Cha et al. 2000), independent of DSB and synaptonemal complex formation. Such a dual role was also proposed for Rec12 (Sharif et al. 2002). The rec12 $\Delta$ mutant showed frequent non-disjunction in meiosis I. This phenotype was much milder in the rec $12 Y 98 F$ active site mutant, implying that Rec12 has a supporting function on chromosomes segregation in meiosis I, besides its activity in DSB formation. However, contradicting results were reported by Davis and Smith (2003). Additional experiments are required to determine whether Rec12-dependent DSB formation occurs in centromeric core regions or whether Rec12 has another role at the centromeres.

\section{Rec12 binding and cohesin}

The correlation between Rec12 binding and Rec 8 binding was strong in the centromeric core regions of chromosome II and III (Fig. 6), but was also evident for the remaining regions tested (Table 3). Partially, this correlation could be explained by the mutual preference of AT-rich sequences: A comparison of Rec 8 binding and GC content revealed indeed an inverse correlation (Spearman correlation $r=$ $-0.14, p<0.0001)$. However, the proximity of Rec12binding peaks to Rec8-binding peaks in more than $60 \%$ of all strong Rec12-binding peaks allow us to conclude that a functional relationship between the two complexes may exist. Rec8 could direct Rec12 to susceptible regions for DSB formation. This could explain a long-known riddle: region-specific reduction of recombination in strains carrying mutations in the genes $r e c 8$, recll, and rec10. Specific 
point mutations in all three genes, as well as rec 8 and rec1l, but not reclo deletion strains, were found to have strongly reduced conversion and crossover frequencies (up to more than 100-fold) in the central parts of the chromosomes, but only a slight (at most 10-fold) reduction at the chromosome ends (DeVeaux and Smith 1994; Li et al. 1997; Parisi et al. 1999). Regional reduction of DSB frequency in rec $8 \Delta$ and rec11 $\Delta$ (both genes coding for cohesin subunits) has been reported (Ellermeier and Smith 2005). Little reduction of recombination at chromosome ends may be due to the presence of mitotic cohesin complexes there during the early stages of meiosis (Kitajima et al. 2003; Yokobayashi et al. 2003). In mitosis, Rec8 and Rec11 are replaced by their paralogs $\operatorname{Rad} 21$ and Psc3 (Kitajima et al. 2003; Yokobayashi et al. 2003). Assistance of mitotic cohesins for the Rec12 complex would then explain the maintenance of higher recombination frequency at chromosome ends in rec 8 and recll mutants. The presence of region-specific recombination reduction in the rec10-109 point mutant (DeVeaux and Smith 1994), but not in other rec10 point mutants (Wells et al. 2006), and complete loss of recombination in a rec10 deletion strain (Ellermeier and Smith 2005; Wells et al. 2006), might indicate that cohesin complexes and Rec12 complexes also interact with the linear element structural protein Rec10 (Lorenz et al. 2006; Molnar et al. 2003) for definition of DSB formation sites.

Acknowledgments We thank Hirofumi Aiba for the gpd1-E13 mutant, Andrea Ludin for writing the information retrieval programs to perform statistical analysis, Chris Penkett for help with the ArrayExpress submission, and Eva Heiniger and Silvia Steiner for construction of the rec6 $\Delta$ and recl $4 \Delta$ strains. We also thank Gareth Cromie and Gerry Smith, HCRC Seattle, for communication of results ahead of publication. The study was supported by the Swiss National Science Foundation to JK, and by Cancer Research UK [CUK], Grant No. C9546/A6517 to JB. KL was supported by a Marie-Heim-Vögtlin fellowship.

\section{References}

Alani E, Padmore R, Kleckner N (1990) Analysis of wild-type and rad50 mutants of yeast suggests an intimate relationship between meiotic chromosome synapsis and recombination. Cell 61:419436

Bähler J, Wu JQ, Longtine MS, Shah NG, McKenzie A 3rd, Steever AB, Wach A, Philippsen P, Pringle JR (1998) Heterologous modules for efficient and versatile PCR-based gene targeting in Schizosaccharomyces pombe. Yeast 14:943-951

Baudat F, Nicolas A (1997) Clustering of meiotic double-strand breaks on yeast chromosome III. Proc Natl Acad Sci U S A 94:5213-5218

Baur M, Hartsuiker E, Lehmann E, Ludin K, Munz P, Kohli J (2005) The meiotic recombination hot spot ura4A in Schizosaccharomyces pombe. Genetics 169:551-561

Beach D, Rodgers L, Gould J (1985) ran1+ controls the transition from mitotic division to meiosis in fission yeast. Curr Genet 10:297-311
Birdsell JA (2002) Integrating genomics, bioinformatics, and classical genetics to study the effects of recombination on genome evolution. Mol Biol Evol 19:1181-1197

Blitzblau HG, Bell GW, Rodriguez J, Bell SP, Hochwagen A (2007) Mapping of meiotic single-stranded DNA reveals double-strandedbreak hotspots near centromeres and telomeres. Curr Biol 17:2003-2012

Borde V, Lin W, Novikov E, Petrini JH, Lichten M, Nicolas A (2004) Association of Mre11p with double-strand break sites during yeast meiosis. Mol Cell 13:389-401

Buck MJ, Nobel AB, Lieb JD (2005) ChIPOTle: a user-friendly tool for the analysis of ChIP-chip data. Genome Biol 6:R97

Buhler C, Borde V, Lichten M (2007) Mapping meiotic single-strand DNA reveals a new landscape of DNA double-strand breaks in Saccharomyces cerevisiae. PLoS Biol 5:e324

Cervantes MD, Farah JA, Smith GR (2000) Meiotic DNA breaks associated with recombination in S. pombe. Mol Cell 5:883-888

Cha RS, Weiner BM, Keeney S, Dekker J, Kleckner N (2000) Progression of meiotic DNA replication is modulated by interchromosomal interaction proteins, negatively by Spo11p and positively by Rec8p. Genes Dev 14:493-503

Cromie GA, Rubio CA, Hyppa RW, Smith GR (2005) A natural meiotic DNA break site in Schizosaccharomyces pombe is a hotspot of gene conversion, highly associated with crossing over. Genetics 169:595-605

Cromie GA, Hyppa RW, Taylor AF, Zakharyevich K, Hunter N, Smith GR (2006) Single Holliday junctions are intermediates of meiotic recombination. Cell 127:1167-1178

Cromie GA, Hyppa RW, Cam HP, Farah JA, Grewal SI, Smith GR (2007) A discrete class of intergenic DNA dictates meiotic DNA break hotspots in fission yeast. PLoS Genet 3:e141

Davis L, Smith GR (2003) Nonrandom homolog segregation at meiosis I in Schizosaccharomyces pombe mutants lacking recombination. Genetics 163:857-874

de Massy B (2003) Distribution of meiotic recombination sites. Trends Genet 19:514-522

DeVeaux LC, Smith GR (1994) Region-specific activators of meiotic recombination in Schizosaccharomyces pombe. Genes Dev 8:203-210

Ding DQ, Sakurai N, Katou Y, Itoh T, Shirahige K, Haraguchi T, Hiraoka Y (2006) Meiotic cohesins modulate chromosome compaction during meiotic prophase in fission yeast. J Cell Biol 174:499-508

Doll E (2005) PhD thesis, University of Bern

Drouaud J, Camilleri C, Bourguignon PY, Canaguier A, Berard A, Vezon D, Giancola S, Brunel D, Colot V, Prum B, Quesneville H, Mezard C (2006) Variation in crossing-over rates across chromosome 4 of Arabidopsis thaliana reveals the presence of meiotic recombination "hot spots". Genome Res 16:106-114

Ellermeier C, Smith GR (2005) Cohesins are required for meiotic DNA breakage and recombination in Schizosaccharomyces pombe. Proc Natl Acad Sci U S A 102:10952-10957

Evans DH, Li YF, Fox ME, Smith GR (1997) A WD repeat protein, Rec14, essential for meiotic recombination in Schizosaccharomyces pombe. Genetics 146:1253-1264

Gerton JL, DeRisi J, Shroff R, Lichten M, Brown PO, Petes TD (2000) Inaugural article: global mapping of meiotic recombination hotspots and coldspots in the yeast Saccharomyces cerevisiae. Proc Natl Acad Sci U S A 97:11383-11390

Glynn EF, Megee PC, Yu HG, Mistrot C, Unal E, Koshland DE, DeRisi JL, Gerton JL (2004) Genome-wide mapping of the cohesin complex in the yeast Saccharomyces cerevisiae. PLoS Biol 2:E259

Gregan J, Rabitsch PK, Sakem B, Csutak O, Latypov V, Lehmann E, Kohli J, Nasmyth K (2005) Novel genes required for meiotic chromosome segregation are identified by a high-throughput knockout screen in fission yeast. Curr Biol 15:1663-1669 
Grimm C, Kohli J, Murray J, Maundrell K (1988) Genetic engineering of Schizosaccharomyces pombe: a system for gene disruption and replacement using the ura4 gene as a selectable marker. Mol Gen Genet 215:81-86

Grishchuk AL (2003) PhD thesis, University of Bern, Switzerland.

Gutz H (1971) Site specific induction of gene conversion in Schizosaccharomyces pombe. Genetics 69:317-337

Gygax A, Thuriaux P (1984) A revised chromosome map of the fission yeast Schizosaccharomyces pombe. Curr Genet 8:85-92

Heichinger C, Penkett CJ, Bähler J, Nurse P (2006) Genome-wide characterization of fission yeast DNA replication origins. Embo $\mathrm{J}$ 25:5171-5179

Hentges P, Van Driessche B, Tafforeau L, Vandenhaute J, Carr AM (2005) Three novel antibiotic marker cassettes for gene disruption and marker switching in Schizosaccharomyces pombe. Yeast 22:1013-1019

Keeney S (2001) Mechanism and control of meiotic recombination initiation. Curr Top Dev Biol 52:1-53

Kirkpatrick DT, Wang YH, Dominska M, Griffith JD, Petes TD (1999) Control of meiotic recombination and gene expression in yeast by a simple repetitive DNA sequence that excludes nucleosomes. Mol Cell Biol 19:7661-7671

Kitajima TS, Yokobayashi S, Yamamoto M, Watanabe Y (2003) Distinct cohesin complexes organize meiotic chromosome domains. Science 300:1152-1155

Kon N, Krawchuk MD, Warren BG, Smith GR, Wahls WP (1997) Transcription factor Mts1/Mts2 (Atf1/Pcr1, Gad7/Pcr1) activates the M26 meiotic recombination hotspot in Schizosaccharomyces pombe. Proc Natl Acad Sci U S A 94:13765-13770

Kong A, Gudbjartsson DF, Sainz J, Jonsdottir GM, Gudjonsson SA, Richardsson B, Sigurdardottir S, Barnard J, Hallbeck B, Masson G, Shlien A, Palsson ST, Frigge ML, Thorgeirsson TE, Gulcher JR, Stefansson K (2002) A high-resolution recombination map of the human genome. Nat Genet 31:241-247

Lambie EJ, Roeder GS (1986) Repression of meiotic crossing over by a centromere (CEN3) in Saccharomyces cerevisiae. Genetics 114:769-789

Lambie EJ, Roeder GS (1988) A yeast centromere acts in cis to inhibit meiotic gene conversion of adjacent sequences. Cell 52:863-873

Li YF, Numata M, Wahls WP, Smith GR (1997) Region-specific meiotic recombination in Schizosaccharomyces pombe: the rec11 gene. Mol Microbiol 23:869-878

Lobry JR (1996) Asymmetric substitution patterns in the two DNA strands of bacteria. Mol Biol Evol 13:660-665

Lorenz A, Estreicher A, Kohli J, Loidl J (2006) Meiotic recombination proteins localize to linear elements in Schizosaccharomyces pombe. Chromosoma 115:330-340

Lyne R, Burns G, Mata J, Penkett CJ, Rustici G, Chen D, Langford C, Vetrie D, Bähler J (2003) Whole-genome microarrays of fission yeast: characteristics, accuracy, reproducibility, and processing of array data. BMC Genomics 4:27

Maleki S, Neale MJ, Arora C, Henderson KA, Keeney S (2007) Interactions between Mei4, Rec114, and other proteins required for meiotic DNA double-strand break formation in Saccharomyces cerevisiae.. Chromosoma 116:471-486

Mata J, Lyne R, Burns G, Bähler J (2002) The transcriptional program of meiosis and sporulation in fission yeast. Nat Genet 32:143-147

Mieczkowski PA, Dominska M, Buck MJ, Gerton JL, Lieb JD, Petes TD (2006) Global analysis of the relationship between the binding of the Bas1p transcription factor and meiosis-specific double-strand DNA breaks in Saccharomyces cerevisiae. Mol Cell Biol 26:1014-1027

Mohrenweiser HW, Tsujimoto S, Gordon L, Olsen AS (1998) Regions of sex-specific hypo- and hyper-recombination identified through integration of 180 genetic markers into the metric physical map of human chromosome 19. Genomics 47:153-162
Molnar M, Parisi S, Kakihara Y, Nojima H, Yamamoto A, Hiraoka Y, Bozsik A, Sipiczki M, Kohli J (2001) Characterization of rec7, an early meiotic recombination gene in Schizosaccharomyces pombe. Genetics 157:519-532

Molnar M, Doll E, Yamamoto A, Hiraoka Y, Kohli J (2003) Linear element formation and their role in meiotic sister chromatid cohesion and chromosome pairing. J Cell Sci 116:1719-1731

Moreno S, Klar A, Nurse P (1991) Molecular genetic analysis of fission yeast Schizosaccharomyces pombe. Methods Enzymol 194:795-823

Munz P (1994) An analysis of interference in the fission yeast Schizosaccharomyces pombe. Genetics 137:701-707

Nakaseko Y, Adachi Y, Funahashi S, Niwa O, Yanagida M (1986) Chromosome walking shows a highly homologous repetitive sequence present in all the centromere regions of fission yeast. Embo J 5:1011-1021

Neale MJ, Pan J, Keeney S (2005) Endonucleolytic processing of covalent protein-linked DNA double-strand breaks. Nature 436:1053-1057

Nicolas A, Treco D, Schultes NP, Szostak JW (1989) An initiation site for meiotic gene conversion in the yeast Saccharomyces cerevisiae. Nature 338:35-39

Nurse P (1975) Genetic control of cell size at cell division in yeast. Nature 256:547-551

Ohmiya R, Yamada H, Nakashima K, Aiba H, Mizuno T (1995) Osmoregulation of fission yeast: cloning of two distinct genes encoding glycerol-3-phosphate dehydrogenase, one of which is responsible for osmotolerance for growth. Mol Microbiol 18:963-973

Parisi S, McKay MJ, Molnar M, Thompson MA, van der Spek PJ, van Drunen-Schoenmaker E, Kanaar R, Lehmann E, Hoeijmakers JH, Kohli J (1999) Rec8p, a meiotic recombination and sister chromatid cohesion phosphoprotein of the Rad21p family conserved from fission yeast to humans. Mol Cell Biol 19:3515-3528

Penkett CJ, Birtle ZE, Bahler J (2006) Simplified primer design for PCR-based gene targeting and microarray primer database: two web tools for fission yeast. Yeast 23:921-928

Prieler S, Penkner A, Borde V, Klein F (2005) The control of Spo11's interaction with meiotic recombination hotspots. Genes Dev 19:255-269

Sakem B (2005) PhD thesis, University of Bern. In:

Segurado M, de Luis A, Antequera F (2003) Genome-wide distribution of DNA replication origins at A+T-rich islands in Schizosaccharomyces pombe. EMBO Rep 4:1048-1053

Sharif WD, Glick GG, Davidson MK, Wahls WP (2002) Distinct functions of $S$. pombe Rec12 (Spo11) protein and Rec12dependent crossover recombination (chiasmata) in meiosis I; and a requirement for Rec12 in meiosis II. Cell Chromosome 1:1

Shimada T, Yamashita A, Yamamoto M (2003) The fission yeast meiotic regulator Mei2p forms a dot structure in the horse-tail nucleus in association with the sme2 locus on chromosome II. Mol Biol Cell 14:2461-2469

Steiner WW, Smith GR (2005) Natural meiotic recombination hot spots in the Schizosaccharomyces pombe genome successfully predicted from the simple sequence motif M26. Mol Cell Biol 25:9054-9062

Steiner WW, Schreckhise RW, Smith GR (2002) Meiotic DNA breaks at the $S$. pombe recombination hot spot M26. Mol Cell 9:847-855

Tesse S, Storlazzi A, Kleckner N, Gargano S, Zickler D (2003) Localization and roles of Ski8p protein in Sordaria meiosis and delineation of three mechanistically distinct steps of meiotic homolog juxtaposition. Proc Natl Acad Sci U S A 100:12865-12870

Watanabe T, Miyashita K, Saito TT, Nabeshima K, Nojima H (2002) Abundant poly(A)-bearing RNAs that lack open reading frames in Schizosaccharomyces pombe. DNA Res 9:209-215 
Wells JL, Pryce DW, Estreicher A, Loidl J, McFarlane RJ (2006) Linear element-independent meiotic recombination in Schizosaccharomyces pombe. Genetics 174:1105-1114

Winckler W, Myers SR, Richter DJ, Onofrio RC, McDonald GJ, Bontrop RE, McVean GA, Gabriel SB, Reich D, Donnelly P, Altshuler D (2005) Comparison of fine-scale recombination rates in humans and chimpanzees. Science 308:107-111

Wood V, Gwilliam R, Rajandream MA, Lyne M, Lyne R, Stewart A, Sgouros J, Peat N, Hayles J, Baker S, Basham D, Bowman S, Brooks K, Brown D, Brown S, Chillingworth T, Churcher C, Collins M, Connor R, Cronin A, Davis P, Feltwell T, Fraser A, Gentles S, Goble A, Hamlin N, Harris D, Hidalgo J, Hodgson G, Holroyd S, Hornsby T, Howarth S, Huckle EJ, Hunt S, Jagels K, James K, Jones L, Jones M, Leather S, McDonald S, McLean J, Mooney P, Moule S, Mungall K, Murphy L, Niblett D, Odell C, Oliver K, O'Neil S, Pearson D, Quail MA, Rabbinowitsch E, Rutherford K, Rutter S, Saunders D, Seeger K, Sharp S, Skelton J, Simmonds M, Squares R, Squares S, Stevens K, Taylor K, Taylor RG, Tivey A, Walsh S, Warren T, Whitehead S, Woodward J, Volckaert G, Aert R, Robben J, Grymonprez B, Weltjens I, Vanstreels E, Rieger M, Schafer M, Muller-Auer S, Gabel C, Fuchs M, Dusterhoft A, Fritzc C, Holzer E, Moestl D, Hilbert H, Borzym K, Langer I, Beck A, Lehrach H, Reinhardt R, Pohl TM, Eger P, Zimmermann W, Wedler H, Wambutt R, Purnelle B, Goffeau A, Cadieu E, Dreano S, Gloux S, Lelaure V, Mottier S, Galibert F, Aves SJ, Xiang Z, Hunt C, Moore K, Hurst SM, Lucas M, Rochet M, Gaillardin C, Tallada VA, Garzon A,
Thode G, Daga RR, Cruzado L, Jimenez J, Sanchez M, del Rey F, Benito J, Dominguez A, Revuelta JL, Moreno S, Armstrong J, Forsburg SL, Cerutti L, Lowe T, McCombie WR, Paulsen I, Potashkin J, Shpakovski GV, Ussery D, Barrell BG, Nurse P (2002) The genome sequence of Schizosaccharomyces pombe. Nature 415:871-880

Xu F, Petes TD (1996) Fine-structure mapping of meiosis-specific double-strand DNA breaks at a recombination hotspot associated with an insertion of telomeric sequences upstream of the HIS4 locus in yeast. Genetics 143:1115-1125

Yamada T, Mizuno KI, Hirota K, Kon N, Wahls WP, Hartsuiker E, Murofushi H, Shibata T, Ohta K (2004) Roles of histone acetylation and chromatin remodeling factor in a meiotic recombination hotspot. Embo J 23:1792-1803

Yamamoto A, Hiraoka Y (2003) Monopolar spindle attachment of sister chromatids is ensured by two distinct mechanisms at the first meiotic division in fission yeast. Embo J 22:2284-2296

Yokobayashi S, Yamamoto M, Watanabe Y (2003) Cohesins determine the attachment manner of kinetochores to spindle microtubules at meiosis I in fission yeast. Mol Cell Biol 23:3965-3973

Young JA, Schreckhise RW, Steiner WW, Smith GR (2002) Meiotic recombination remote from prominent DNA break sites in $S$. pombe.. Mol Cell 9:253-263

Yu A, Zhao C, Fan Y, Jang W, Mungall AJ, Deloukas P, Olsen A, Doggett NA, Ghebranious N, Broman KW, Weber JL (2001) Comparison of human genetic and sequence-based physical maps. Nature 409:951-953 